\title{
Evaluation of Oil Producing Potential of a New Isolate-Chlorella lewinii SUB3545914 for Biodiesel Production under Heterotrophic Cultivation
}

\author{
Innocent Okonkwo Ogbonna1,2*, James Chukwuma Ogbonna ${ }^{2}$ \\ ${ }^{1}$ Department of Microbiology, University of Agriculture, Makurdi, Nigeria \\ ${ }^{2}$ Department of Microbiology, University of Nigeria, Nsukka, Nigeria \\ Email: *innocentia09@yahoo.com, James.ogbonna@unn.edu.ng
}

How to cite this paper: Ogbonna, I.O. and Ogbonna, J.C. (2018) Evaluation of Oil Producing Potential of a New IsolateChlorella lewinii SUB3545914 for Biodiesel Production under Heterotrophic Cultivation. Journal of Sustainable Bioenergy Systems, 8, 67-81.

https://doi.org/10.4236/jsbs.2018.83005

Received: August 21, 2018

Accepted: September 23, 2018

Published: September 26, 2018

Copyright $\odot 2018$ by authors and Scientific Research Publishing Inc. This work is licensed under the Creative Commons Attribution International License (CC BY 4.0).

http://creativecommons.org/licenses/by/4.0/

\begin{abstract}
Microalgae with high oil productivities are most desired in biodiesel production. Chlorella lewinii SUB3545914, was isolated and assessed for its growth rates, lipid productivities and fatty acid profiles under heterotrophic cultivation. The alga was isolated after enrichment in $\mathrm{BG}-11$ medium $(\mathrm{pH}=7.3)$ under a light intensity of approximately $17.5 \mu \mathrm{E} \cdot \mathrm{m}^{-2} \cdot \mathrm{s}^{-1}$ at $30^{\circ} \mathrm{C} \pm 2^{\circ} \mathrm{C}$. In addition to morphology, polymerase chain reaction (PCR) and metagenomics were used for isolate identification. The DNA was sequenced and multiple sequence alignment of the BLASTED results revealed $95 \%$ similarity to Chlorella lewinii. Maximum growth $\left(3.15 \pm 0.06 \mathrm{~g} \cdot \mathrm{L}^{-1}\right)$, lipid content (44.0\%) and lipid volumetric productivities $\left(118.80 \pm 3.02 \mathrm{mg} \cdot \mathrm{L}^{-1} \cdot\right.$ day $\left.^{-1}\right)$ in glucose supplemented media were more appreciable in comparison with the glycerol counterparts. Similarly, the highest growth $\left(2.03 \pm 0.68 \mathrm{~g} \cdot \mathrm{L}^{-1}\right)$, lipid content $(31.47 \%)$ and lipid productivities $\left(47.21 \pm 2.08 \mathrm{mg} \cdot \mathrm{L}^{-1} \cdot \mathrm{day}^{-1}\right)$ in glycerol supplemented media were more than those got under autotrophic cultivation. Chlorophyll contents did not vary remarkably in heterotrophic cultures. The major fatty acids obtained by Gas Chromatography Mass Spectrometry (GC-MS) were oleic and Octadecanoic acids for all the culture conditions. Chlorella lewinii is appropriate for accumulating lipids for biodiesel under heterotrophic cultivation on glucose because of high lipid volumetric productivities.
\end{abstract}

\section{Keywords}

Biodiesel, Chlorella lewinii, Fatty Acid Contents, Heterotrophic Culture, Microalgal Biomass Content, Microalgal Lipid Accumulation 


\section{Introduction}

The demand for petroleum products is increasing because of the rising world population and industrialization. Although petro-diesel is currently cheaper than biodiesel, the interest in the development of technologies for the production of biodiesel has been on the increase due to its production from renewable biological sources. It is ecologically friendly, releasing comparatively very little carbon monoxide, much less hydrocarbons particulate matter (HPM) and no sulfur and aromatic compounds to the environment during combustion [1]. In addition, it is biodegradable, non-toxic and safe to handle. The problems with the use of fossil fuels include non-renewability, non-sustainability, an unpredictability of global prices and various environmental problems associated with their drilling, transportation, and ultimate use.

Feedstock from biomasses is robustly being exploited for possible substitution of the ecologically non-friendly fossilized resources. Consequently, vegetable oils have been the key candidate in this pursuit. A major demerit of the use of this oil is that biodiesel produced from vegetable oils is usually expensive. In addition, they contain high proportions of undesirable free fatty acids (FFA) that constitute serious conversion problems during transesterification [2]. Besides, the use of vegetable oil as feedstock for fuel has been controversial because of the possible effects on food security. Chisti [3] had revealed that microalgae are the best candidates for lipid and biodiesel production. Griffith and Harrison [4] added that lipid productivity plays the most crucial role in biodiesel production. Consequently, isolation of a good oil-producing species is critical in biodiesel production.

Microalgae with high oil productivities are most desired in biodiesel production. The obvious reasons for use of microalgae include fast growth rate [5] and high oil contents [6]. Besides, land usage by microalgae is smaller when compared with the requirements of conventional crops [7] and microalgae have a high carbon sequestration rate [8]. They can also grow on marginal lands not suitable for the growth of conventional crops. However, the major challenge which questions the feasibility of use of microalgae for biodiesel production is the lipid volumetric productivities [4] and the lipid class. Microalgae cultures have been previously assessed with a view to finding the optimum conditions for growth and lipid accumulation. Some of these reports [9] [10] showed that the mode of cultivation (including autotrophic, mixotrophic or heterotrophic) has significant effects on cell growth, lipid contents and lipid productivities. Xu et al. [9] and Azama et al. [11] showed that heterotrophic cultures produce more biomass than their photoautotrophic counterparts.

Besides, some heterotrophically cultivated microalgae produce higher oils than their photoautotrophic counterparts [9] [12] [13] [14] [15]. Consequently, heterotrophic microalgal cultivation could offer a better prospect for biodiesel production. In a scenario where the biomass and oil contents of microalgae are high as imagined above, lipid productivity will consequently be high. This, in 
turn, will lead to increase in biodiesel production since oil productivity is a function of biomass productivities and oil contents. Oil productivity of $179 \mathrm{mg} \cdot \mathrm{L}^{-1} \cdot \mathrm{d}^{-1}$ obtained in phototrophic cultures was regarded to be a very high achievement [16]. Some authors, however, obtained much high oil productivity in heterotrophic cultures than was done in the photoautotrophic conditions [9] [17] [18] [19] [20]. Microalgal optimal production systems have been under research pressures because technically speaking industrial scale production of biodiesel has been saddled with enough challenges. These bottlenecks do not exclude the economic non-feasibility of biodiesel production system when compared with the fossil fuel production system.

The study investigated the oil producing potential of a novel microalgaChlorella lewinii SUB3545914.

\section{Materials and Methods}

\subsection{The Microalga and Culture Conditions}

The microalga, Chlorella lewinii was isolated from a fresh water body in North East Nigeria [21]. The water sample was enriched by photoautotrophic cultivation in a transparent Roux bottle containing BG-11 medium. It was incubated at a light intensity of about $17.5 \mu \mathrm{E} \cdot \mathrm{m}^{-2} \cdot \mathrm{s}^{-1}$ (1000 lux) and temperature of $30^{\circ} \mathrm{C} \pm$ $2^{\circ} \mathrm{C}$ (simulating the light intensity and temperature of its natural freshwater environment where the isolation was done). The microalga was purified on a sterile agar medium containing BG-11 and $15 \mathrm{~g} \cdot \mathrm{L}^{-1}$ agar. The ability of the microalga to grow heterotrophically was investigated by inoculating the isolate into BG-11 medium supplemented with various concentrations of glucose $(10,20,30$ and $\left.40 \mathrm{~g} \cdot \mathrm{L}^{-1}\right)$ or glycerol $\left(0.25 ; 0.5 ; 0.75\right.$ and $\left.1.0 \mathrm{~mL} \cdot \mathrm{L}^{-1}\right)$. Prior to the addition of glucose or glycerol, the initial medium $\mathrm{pH}$ was adjusted to 7.3 using dilute Sodium hydroxide $(\mathrm{NaOH})$ and Hydrochloric acid $(\mathrm{HCl})$ solutions. The cultivation was done in $2000 \mathrm{~mL}$ dark colored Teflon plastic bottles containing $1000 \mathrm{~mL}$ of the medium [21]. A seed culture (algal culture for inoculation) was obtained by inoculating a BG-11 medium supplemented with $10 \mathrm{~g} \cdot \mathrm{L}^{-1}$ of glucose or $10 \mathrm{~mL} \cdot \mathrm{L}^{-1}$ of glycerol, followed by incubation for 7 days in the dark. This seed culture (150 $\mathrm{mL}$ ) was used to inoculate $1000 \mathrm{~mL}$ of the main culture. The cultures were incubated at room temperature $\left(30^{\circ} \mathrm{C} \pm 2^{\circ} \mathrm{C}\right)$ in the dark for 12 days. All the cultures were shaken twice a day in a Gallenkamp orbital shaker (Gallenkamp Ltd, United Kingdom) at 120 revolutions per minute (rpm) for three minutes. For the analyses of biomass, chlorophyll, and lipids, $10 \mathrm{~mL}$ sample each was taken every 2 days and analyzed. All experiments were done in triplicates and the results presented as means \pm the standard deviation.

\subsection{DNA Extraction}

The algal culture broth sample was centrifuged at 14,000 revolutions per minute $(\mathrm{rpm})$ for $10 \mathrm{~min}$ in a micro-centrifuge (Eppendorf ${ }^{\mathrm{TM}} 5424$ Micro-centrifuge). This was washed 3 times using $1 \mathrm{~mL}$ of ultra-pure water with another centrifu- 
gation at 12,000 rpm for $5 \mathrm{~min}$. DNA extraction and purification were done using ZRSoil DNA MiniPrep ( ${ }^{\mathrm{TM}} 50$ Preps, Model D6001, Zymo Research, California, USA). A $50-100 \mathrm{mg}$ of the cells was suspended in $200 \mu \mathrm{L}$ of sterile water and was transferred into a lysis tube (ZRBashingBead ${ }^{\mathrm{TM}}$ ). This was followed by the addition of $750 \mu \mathrm{L}$ of lysis solution. The bead containing the solution was added to the bead beater which had a $2 \mathrm{~mL}$ tube holder fitted to it. This was spun at $12,000 \mathrm{rpm}$ for $5 \mathrm{~min}$ according to the method reported by Ogbulie and Nwaokorie [22]. The lysis tube was centrifuged (10,000 rpm for $1 \mathrm{~min})$ and a 400 $\mu \mathrm{L}$ of the supernatant was pipetted into a Spin Filter (Zymo-Spin $\left.{ }^{\mathrm{TM}} \mathrm{IV}\right)$ in a collection tube and centrifuged (7000 rpm for $1 \mathrm{~min}$ ).Thereafter, $1200 \mu \mathrm{L}$ of soil DNA binding buffer was added into the filtrate tubeas reported by Ogbulie and Nwaokorie [22]. This was followed by the addition of $800 \mu \mathrm{L}$ of the mixture into a column (Zymo-Spin $\left.{ }^{\mathrm{TM}} \mathrm{IIC}\right)$ in a collection tube and centrifuged (10,000 rpm for $1 \mathrm{~min}$ ). The flow through was discarded from the collection tube and the process was repeated to obtain the remaining products. The $200 \mu \mathrm{L}$ DNA pre-wash buffer was added into the column (Zymo-Spin ${ }^{\mathrm{TM}} \mathrm{IIC}$ ) in a new collection tube and centrifuged (10,000 rpm for $1 \mathrm{~min})$. This was followed by the addition of $500 \mu \mathrm{L}$ of soil DNA wash buffer into the column (Zymo-Spin ${ }^{\mathrm{TM}} \mathrm{IIC}$ ) and was centrifuged $(10,000 \mathrm{rpm}$ for $1 \mathrm{~min})$. The column (Zymo-Spin $\left.{ }^{\mathrm{TM}} \mathrm{IIC}\right)$ was transferred into a clean $1.5 \mathrm{~mL}$ micro-centrifuge tube and $100 \mu \mathrm{L}$ of DNA ElutionBuffer was then added directly to the column matrix. This was centrifuged at 10,000 rpm for $30 \mathrm{~s}$ to elute the DNA. The ultrapure resulting filtrate (DNA) obtained was used as a template during the assay. This was transported in ice for the laboratory sequencing.

\subsection{DNA Amplification and Sequencing}

Identification of the isolate utilised18SrRNA sequencing with ITS- 1 and ITS- 4 as universal primers. The primer sequences were $18 \mathrm{~S}$

forward-'TTTCTGCCCTATCAACTTTCGATG'

$18 \mathrm{~S}$ reverse-'TACAAAGGGCAGGGACGTAAT"

ITS-1 TCCGTAGGTGAACCTGCG G

ITS-4 TCCTCCGCT TAT TGA TAT GC

Sequencing was done by Sanger dideoxy sequencing method (Sanger Sequencer $^{\mathrm{TM}}$ 3730/3730XL) DNA Analyzers. The result was analyzed by direct blasting on http://blast.ncbi.nlm.nih.gov. The BLAST results show top hits with minimum E-score (0.0) and 95\% - 100\% identical similarities were used to identify the alga.

\subsection{Determination of Biomass Concentration}

Biomass concentrations were measured at a two-day interval until a stationary phase was reached, and the specific growth rate $(\mu)$ was calculated as according to Liang et al. [23] in Equation (1).

$$
\mu=\frac{\left(\ln N_{t}-\ln N_{0}\right)}{t-t_{0}}
$$


where $N_{t}=$ cell density at a time $(t)$ and $N_{0}=$ cell density at the start of the exponential phase $\left(t_{0}\right)$.

\subsection{Determination of Cell Dry Weight}

A $10 \mathrm{~mL}$ sample of the culture broth was centrifuged ( $3000 \mathrm{X} \mathrm{g}$ for $20 \mathrm{~min}$ ) and the pellets washed three times by further centrifugation ( $3000 \mathrm{X} \mathrm{g}$ for $10 \mathrm{~min}$ ) using sterile deionized water. The weight of the wash $\left(W_{1}\right)$ was recorded, followed by drying in an air oven $\left(70^{\circ} \mathrm{C}\right)$ for 6 - $8 \mathrm{~h}$ until a constant weight was obtained and then re-weighed $\left(W_{2}\right)$.

$$
\begin{array}{r}
\text { Cell Dry Weight }(\mathrm{CDW})=W_{2}-W_{1} \\
\text { Converting to } \mathrm{g} \cdot \mathrm{L}^{-1}, \mathrm{CDW}\left(\frac{g}{L}\right)=\frac{W_{2}-W_{1}}{V} \times \frac{1000}{1}
\end{array}
$$

where: $w_{2}=$ weight of filter paper and dried cells $(\mathrm{g})$

$W_{1}=$ weight of filter paper $(\mathrm{g})$

$V=$ volume of culture $(\mathrm{mL})$

\subsection{Chlorophyll Extraction and Quantification}

Methanol and water were used to extract chlorophyll using the method of Becker [24]. Algal pellets obtained from the centrifugation of $10 \mathrm{~mL}$ algal suspension at $3000 \mathrm{rpm}$ (for $30 \mathrm{~min}$ ) was used to determine the chlorophyll (ChI) content. The pellet was suspended in $3 \mathrm{~mL}$ of methanol and boiled in a water bath for $5 \mathrm{~min}$. This was allowed to cool to room temperature and was subsequently made up to a $5 \mathrm{~mL}$ volume by the addition of methanol. Chlorophyll concentration was quantified by reading the absorption (A) of the pigment extract in a spectrophotometer (SpectrumLab 22) at a given wavelength against a solvent blank using the equation:

$$
\begin{gathered}
\text { Chlorophyll } a\left(\mathrm{mg} \cdot \mathrm{L}^{-1}\right)=\left(16.5 \times A_{665}\right)-\left(8.3 \times A_{650}\right) \\
\text { Chlorophyll } b\left(\mathrm{mg} \cdot \mathrm{L}^{-1}\right)=\left(33.8 \times A_{650}\right)-\left(12.5 \times A_{665}\right) \\
\text { Chlorophyll } a+b\left(\mathrm{mg} \cdot \mathrm{L}^{-1}\right)=\left(4.0 \times A_{665}\right)-\left(225.5 \times A_{650}\right)
\end{gathered}
$$

\subsection{Determination of Lipid Contents}

The lipid content of the microalga was extracted from the dry cell mass using the protocol of Bligh and Dyer [25]. Methanol, chloroform, and water were used for the extraction. The extracted oil was left in a vial of known weight in a water bath $\left(55^{\circ} \mathrm{C}\right)$ under constant nitrogen supply to evaporate the chloroform. Lipid productivity was derived from an equation from Griffiths and Harrison [4] and was expressed in $\mathrm{g} \cdot \mathrm{L}^{-1} \cdot \mathrm{day}^{-1}(6)$.

$$
\text { Lipid productivity }\left(\mathrm{g} \cdot \mathrm{L}^{-1} \cdot \mathrm{d}^{-1}\right)=\frac{\text { Total algae biomass }(g) \times \text { lipid content }(\%)}{\text { Working volume }(i) \times \text { Cultivation time }(d)}
$$




\subsection{Determination of Fatty Acid Contents and Composition}

Fatty acid content of the algal oil was determined by gas chromatography mass spectrometry (GC-MS) (Shimadzu, Japan, Model GCMS-QP 2010 Plus) [21] [26] [27].

\subsection{Statistics}

The data generated from the research were analyzed using Statistical Package for Social Sciences (SPSS) version 16.0. One way analysis of variance and other descriptive statistics were employed.

\section{Results}

\subsection{Identification of the Microalga}

Microscopic examination of the isolate showed that it has an oval to circular unicellular structure appearing singly except for dividing cells that appeared double. The full nucleotide sequence information is given in the supplementary section. Multiple alignment of the amplified sequence revealed $95 \%$ sequence similarity to Chlorella lewinii (Table 1). The isolate had a partial sequence of an internal transcribed spacer 1; 5.8S ribosomal RNA gene, complete sequence of internal transcribed spacer 2 and $28 \mathrm{~S}$ ribosomal RNA gene, partial sequence. The isolate is a green alga. Lineage report showed that the microalga belongs to the phylum Chlorophyta; class Trebouxiophyceae, order Chlorellales, family Chlorellaceae, genus Chlorella; and species Chlorella lewinii.

\subsection{Effects of Glucose Concentration on Growth and Lipid Contents of Chlorella lewinii SUB3545914}

The effects of glucose concentration as the sole carbon source on the growth and lipid contents of Chlorella lewinii are presented in Figure 1. There seemed to be a direct relationship between glucose concentration and the final biomass concentration. The maximum biomass concentrations were obtained on the $10^{\text {th }}$ day of incubation with range of values of between $2.04 \pm 0.12$ and $3.15 \pm 0.06 \mathrm{~g} \cdot \mathrm{L}^{-1}$ dry cell weight. The specific growth rates ranged from $0.17 \pm 0.03$ to $0.19 \pm 0.01$ $\mu \cdot \mathrm{d}^{-1}$. The highest lipid content (44\%) was obtained in medium supplemented with $4 \%$ glucose (Figure 1).

There was no statistically significant difference $(\mathrm{p}<0.05)$ in the lipid concentration at the exponential and stationary growth phases in the media with $2 \%$ and $4 \%$ glucose. The maximum chlorophyll $\mathrm{a}+\mathrm{b}$ contents obtained in this study ranged from $3.30 \pm 0.03$ to $5.50 \pm 0.04 \mathrm{mg} \cdot \mathrm{g}^{-1}$ cell (Table 2 ). The highest lipid productivity $\left(118.80 \pm 3.02 \mathrm{mg} \cdot \mathrm{L}^{-1} \cdot \mathrm{day}^{-1}\right)$ was obtained in the heterotrophic culture with $4 \%$ glucose. Biomass yield was inversely proportional to the medium glucose concentration with a range of 0.079 to 0.204 . In the entire test parameters, the growth of the alga in BG-11 medium with $1 \%$ glucose supplement produced the lowest biomass concentration and lipid productivity-however; it had the highest biomass and lipid yields. 


\subsection{Effects of Glycerol Concentration on Growth and Lipid Contents of Chlorella lewinii SUB3545914}

The glycerol concentration that supported the highest cell growth was 0.25 $\mathrm{mL} \cdot \mathrm{L}^{-1}$ (Figure 2). There was no general relationship between the glycerol and biomass concentrations. However, the highest biomass concentration was achieved in the medium having the lowest glycerol level. There was a defined lag phase between days 0 and 4 of incubation. Peak algal biomass concentration was achieved on the $8^{\text {th }}$ day regardless of the glycerol concentration. The maximum biomass concentrations owing to the different medium glycerol ranged from $1.69 \pm 0.31$ to $2.03 \pm 0.68 \mathrm{~g} \cdot \mathrm{L}^{-1}$ dry cell weights. Biomass yield was inversely proportional to the medium glycerol concentration. The lipid contents varied with glycerol concentrations. The highest lipid accumulation (31.47\%) was obtained when the medium glycerol level was the highest $\left(1.0 \mathrm{~mL} \cdot \mathrm{L}^{-1}\right)$ while the lowest lipid content (17.1\%) was obtained in a medium containing $0.25 \mathrm{~mL} \cdot \mathrm{L}^{-1}$ glycerol (Figure 2). The lipid content at the exponential growth phase was statistically related $(\mathrm{p}<0.05)$ with that of the stationary growth phase. The range of specific growth rate was from $0.12 \pm 0.02$ to $0.16 \pm 0.01 \mu \cdot \mathrm{d}^{-1}$. Biomass productivity and chlorophyll contents showed no statistically significant $(\mathrm{p}<0.05)$ variation with glycerol concentration (Table 3 ). The lipid productivity was highest $\left(47.21 \pm 2.08 \mathrm{mgL}^{-1} \cdot \mathrm{day}^{-1}\right)$ in the culture with $0.1 \%$ glycerol whereas lipid yield was highest when the medium glycerol concentration was lowest.

\subsection{Comparison of Phototrophic and Heterotrophic Cultivation of Chlorella lewinii SUB3545914}

Comparison of the maximum cell growth and lipid production under photoautotrophic and heterotrophic cultivation of Chlorella lewinii is presented in Table

4. The biomass concentrations obtained in heterotrophic cultures with glucose

Table 1. Results of the BLAST and multiple alignment of the amplified sequences.

\begin{tabular}{cccccccc}
\hline S/No & Strain & Max score & Total score & Query cover (\%) & E value & Identity (\%) & Accession \\
\hline 1 & Chlorella lewinii KU213 & 1203 & 1203 & 97 & 0.0 & 95 & KM061460 \\
2 & Chlorella lewinii KU217 & 1197 & 1197 & 97 & 0.0 & 95 & KM061462 \\
3 & Chlorella lewinii KU215 & 1197 & 1197 & 97 & 0.0 & 95 & KM061461 \\
4 & Chlorella lewinii KU220 & 1192 & 1192 & 97 & 0.0 & 95 & KM061464 \\
5 & Chlorella lewinii KU201 & 1181 & 1181 & 97 & 0.0 & 95 & KM061450 \\
6 & Chlorella lewinii & 1177 & 1177 & 90 & 0.0 & 97 & LC172265 \\
7 & Chlorella lewinii & 1166 & 1166 & 96 & 0.0 & 94 & FM205861 \\
8 & Chlorella lewinii spIso4 & 813 & 813 & 99 & 0.0 & 86 & JX041600 \\
9 & Chlorella lewinii KU209 & 795 & 795 & 97 & 0.0 & 86 & KM061458 \\
10 & Chlorella & & & & & & KP64522 \\
\hline
\end{tabular}


Table 2. Chlorophyll contents, biomass and lipid productivities by Chlorella lewinii SUB3545914 grown in BG-11 medium with different initial glucose concentration.

\begin{tabular}{ccccccc}
\hline $\begin{array}{c}\text { Glucose } \\
\text { concentration }\left(\mathrm{g} \cdot \mathrm{L}^{-1}\right)\end{array}$ & $\begin{array}{c}\text { Max. Chlorophyll } \\
\mathrm{a}+\mathrm{b}\left(\mathrm{mg} \cdot \mathrm{g}^{-1} \text { cell }\right)\end{array}$ & $\begin{array}{c}\text { Specific growth } \\
\text { rate, }\left(\mu \mathrm{d}^{-1}\right)\end{array}$ & $\begin{array}{c}\text { Max. Biomass } \\
\text { concentration }\left(\mathrm{gL}^{-1}\right)\end{array}$ & $\begin{array}{c}\text { Biomass productivity } \\
\left(\mathrm{g} \cdot \mathrm{L}^{-1} \cdot \mathrm{day}^{-1}\right)\end{array}$ & $\begin{array}{c}\text { Lipid content } \\
(\%)\end{array}$ & $\begin{array}{c}\text { Lipid productivity } \\
\left(\mathrm{mg} \cdot \mathrm{L}^{-1} \cdot \mathrm{day}\right.\end{array}$ \\
\hline 10.0 & $3.30 \pm 0.03$ & $0.17 \pm 0.03$ & $2.04 \pm 0.12$ & $0.20 \pm 0.01$ & 28.17 & $56.34 \pm 1.50$ \\
20.0 & $4.50 \pm 0.19$ & $0.18 \pm 0.02$ & $2.49 \pm 0.17$ & $0.25 \pm 0.01$ & 32.33 & $80.83 \pm 2.07$ \\
30.0 & $4.80 \pm 0.25$ & $0.19 \pm 0.03$ & $2.72 \pm 0.29$ & $0.32 \pm 0.02$ & 32.67 & $104.45 \pm 1.05$ \\
40.0 & $5.50 \pm 0.04$ & $0.19 \pm 0.01$ & $3.15 \pm 0.06$ & $0.27 \pm 0.03$ & 44.00 & $118.80 \pm 3.02$ \\
\hline
\end{tabular}

${ }^{\mathrm{a}}$ Results are means of triplicate tests.

Table 3. Chlorophyll contents, biomass and lipid productivities by Chlorella lewinii SUB3545914 grown in BG-11 medium with different initial glycerol concentration.

\begin{tabular}{ccccccc}
\hline $\begin{array}{c}\text { Glycerol concentration } \\
\left(\mathrm{mL} \cdot \mathrm{L}^{-1}\right)\end{array}$ & $\begin{array}{c}\text { Max. Chlorophyll } \\
\mathrm{a}+\mathrm{b}\left(\mathrm{mg} \cdot \mathrm{g}^{-1} \text { cell }\right)\end{array}$ & $\begin{array}{c}\text { Specific growth } \\
\text { rate, }\left(\mu \mathrm{d}^{-1}\right)\end{array}$ & $\begin{array}{c}\text { Max. Biomass } \\
\text { concentration }\left(\mathrm{g} \cdot \mathrm{L}^{-1}\right)\end{array}$ & $\begin{array}{c}\text { Biomass productivity Lipid content } \\
\left(\mathrm{g} \cdot \mathrm{L}^{-1} \cdot \mathrm{day}^{-1}\right)\end{array}$ & $\begin{array}{c}\text { Lipid productivity } \\
(\%)\end{array}$ \\
\hline 0.25 & $4.90 \pm 0.60$ & $0.16 \pm 0.01$ & $2.03 \pm 0.68$ & $0.18 \pm 0.01$ & 22.55 & $40.59 \pm 2.25$ \\
0.50 & $4.50 \pm 0.55$ & $0.15 \pm 0.04$ & $1.84 \pm 0.03$ & $0.16 \pm 0.01$ & 22.03 & $35.25 \pm 0.38$ \\
0.75 & $4.00 \pm 0.30$ & $0.12 \pm 0.01$ & $1.95 \pm 0.13$ & $0.17 \pm 0.02$ & 22.98 & $39.07 \pm 1.15$ \\
1.00 & $3.50 \pm 0.14$ & $0.12 \pm 0.02$ & $1.69 \pm 0.31$ & $0.15 \pm 0.02$ & 31.47 & $47.21 \pm 2.08$ \\
\hline
\end{tabular}

${ }^{\mathrm{b}}$ Results are means of triplicate tests.

Table 4. Comparison of phototrophic and heterotrophic cultivationof Chlorella lewinii SUB3545914.

\begin{tabular}{|c|c|c|c|c|c|c|}
\hline Culture mode & $\begin{array}{l}\text { Max. biomass } \\
\text { conc. }\left(\mathrm{g} \cdot \mathrm{L}^{-1}\right)\end{array}$ & $\begin{array}{l}\text { Max. specific } \\
\text { growth rate } \\
\qquad\left(\mu \mathrm{d}^{-1}\right)\end{array}$ & $\begin{array}{c}\text { Max. lipid } \\
\text { content (\%) }\end{array}$ & $\begin{array}{c}\text { Biomass } \\
\text { productivity } \\
\left(\mathrm{g} \cdot \mathrm{L}^{-1} \cdot \text { day }^{-1}\right)\end{array}$ & $\begin{array}{l}\text { Max. Lipid } \\
\text { productivity } \\
\left(\mathrm{mg} \cdot \mathrm{L}^{-1} \cdot \text { day }^{-1}\right)\end{array}$ & $\begin{array}{l}\text { Max. Chlorophyll } \\
\mathrm{a}+\mathrm{b}\left(\mathrm{mg}^{-1} \mathrm{~g}^{-1} \text { cell }\right)\end{array}$ \\
\hline Photoautotrophic & $1.02 \pm 0.03$ & $0.16 \pm 0.01$ & 16.6 & $0.13 \pm 0.02$ & $21.58 \pm 1.30$ & $39.71 \pm 2.05$ \\
\hline $\begin{array}{c}\text { Heterotrophic } \\
\text { (glucose supplement) }\end{array}$ & $3.15 \pm 0.13$ & $0.35 \pm 0.01$ & 44 & $0.27 \pm 0.3$ & $118.80 \pm 3.02$ & $5.50 \pm 0.04$ \\
\hline $\begin{array}{c}\text { Heterotrophic } \\
\text { (glycerol supplement) }\end{array}$ & $2.03 \pm 0.68$ & $0.19 \pm 0.03$ & 31.47 & $0.15 \pm 0.02$ & $47.21 \pm 2.08$ & $4.90 \pm 0.60$ \\
\hline
\end{tabular}

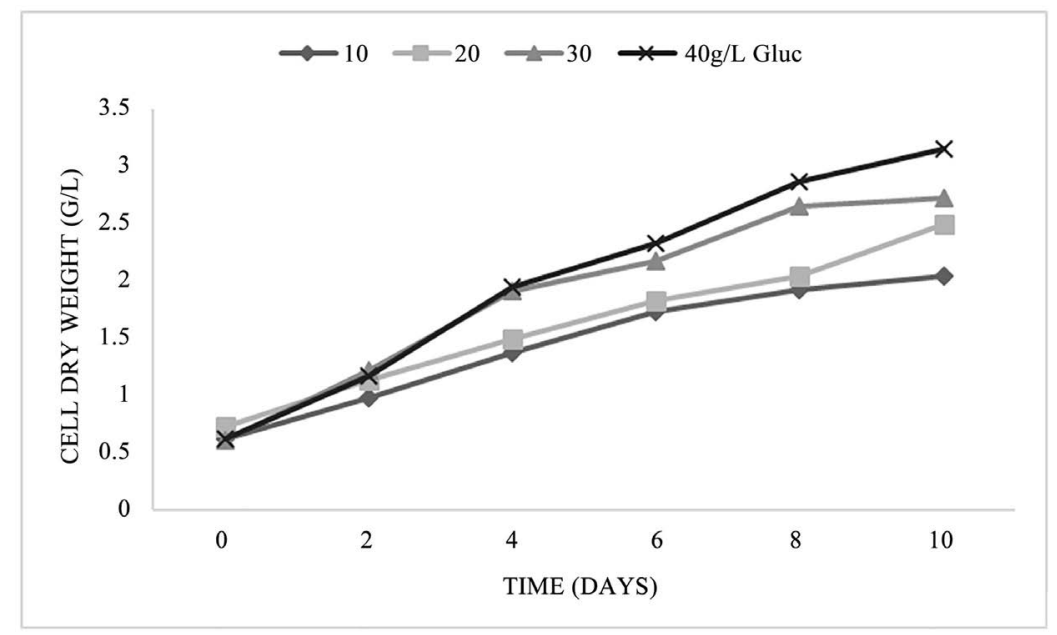

(a) 


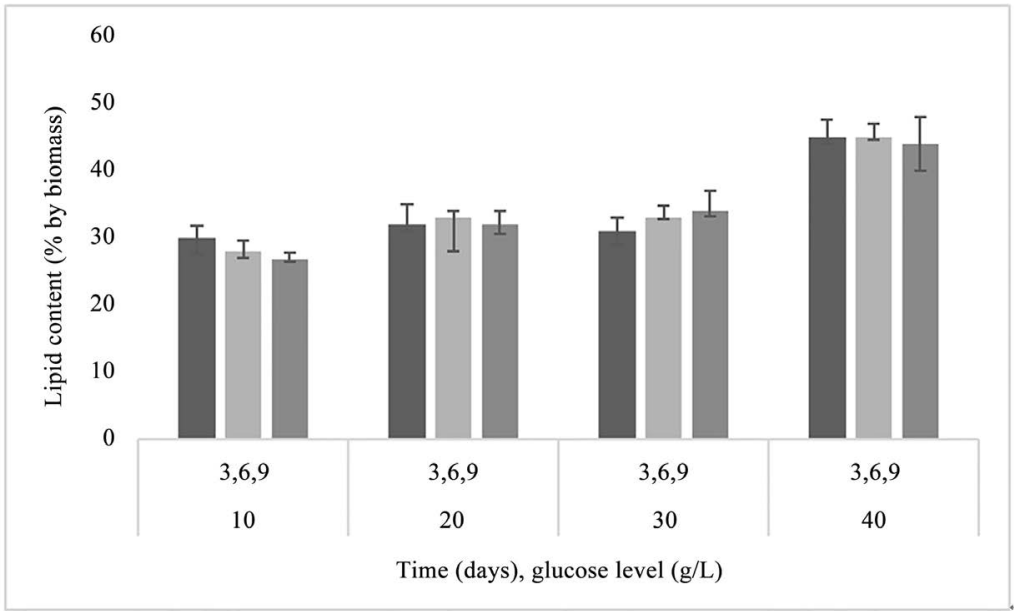

(b)

Figure 1. Effects of levels of glucose on biomass and lipid contents of Chlorella lewinii SUB3545914 [NB: 3, 6, 9 are days 3, 6 and 9 of incubation respectively].

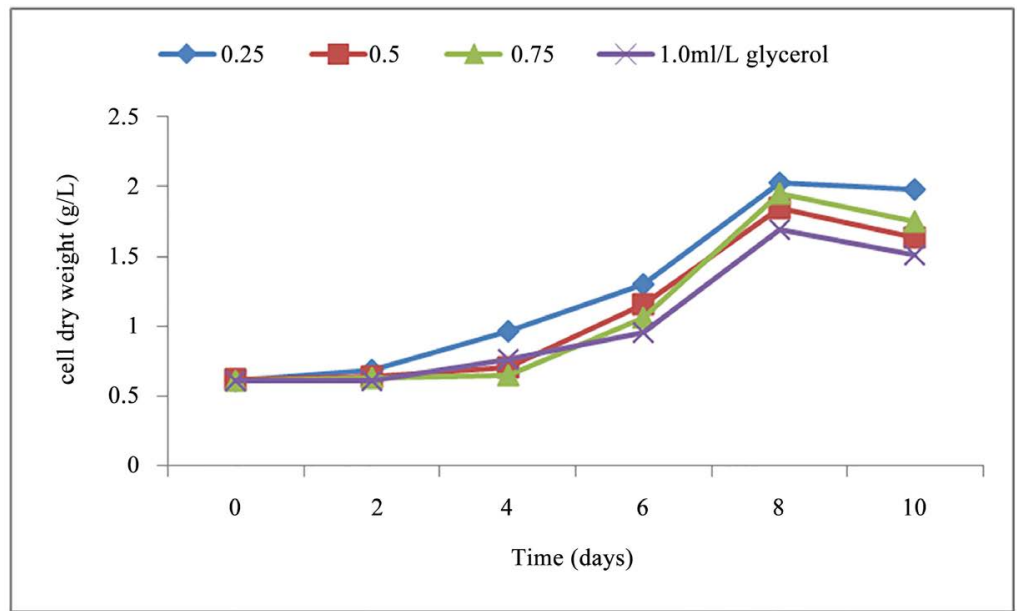

(a)

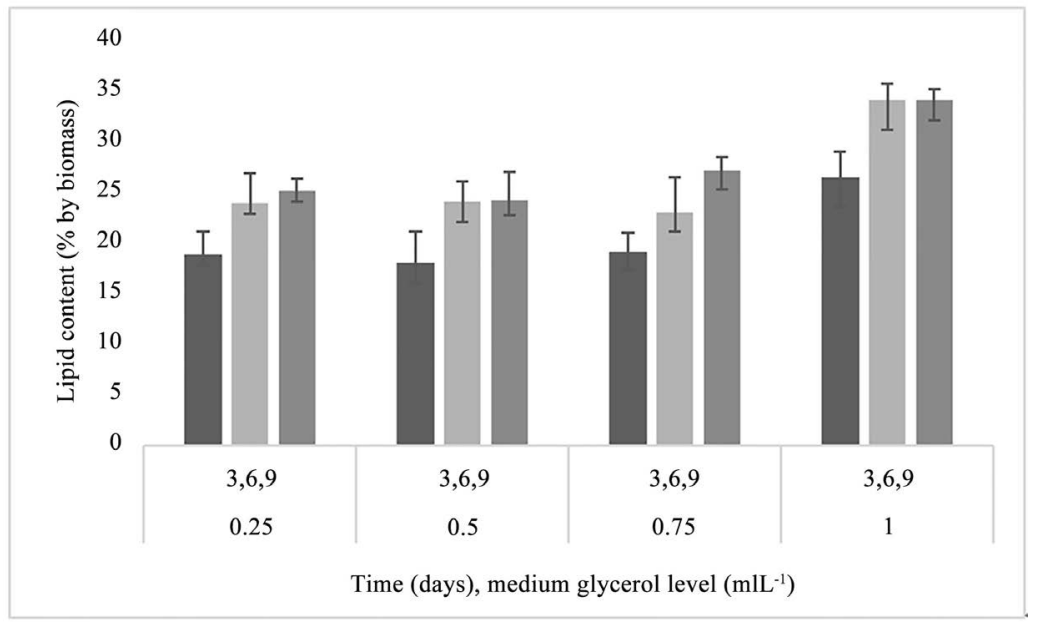

(b)

Figure 2. Effects of levels of glycerol on biomass and lipid contents of Chlorella lewinii SUB3545914 [NB: 3, 6, 9 are days 3, 6 and 9 of incubation respectively]. 
$\left(3.15 \pm 0.13 \mathrm{~g} \cdot \mathrm{L}^{-1}\right)$ and glycerol $\left(2.03 \pm 0.68 \mathrm{~g} \cdot \mathrm{L}^{-1}\right)$ were respectively 5.5 and 2.2-folds higher than the values obtained in photoautotrophic culture but the chlorophyll contents of the alga under photoautotrophic culture condition were 7 times the values obtained in heterotrophic cultures (Table 4). It is important to note that the lipid contents and lipid productivities in heterotrophic cultures with glucose were 2.6 and 5.5 times higher than the values obtained in photoautotrophic culture (Table 4).

Comparison of chemical composition of the oils from Chlorella lewiniiSUB3545914 under different growth conditions showed that major fatty acid obtained was oleic acid (C18:1) for all the culture methods. Other fatty acids were myristic acid (C14:0), stearic acid (C18:0) and linoleic acid (C18:3). Over $70 \%$ of the fatty acids were oleic and stearic acids.

\section{Discussion}

This work has demonstrated, for the first time, that Chlorella lewinii SUB3545914 has the potential for high lipid accumulation. However, other strains of Chlorella have also been used in the production of high lipids for biodiesel [28] [29] [30].

\subsection{Heterotrophic Cultivation of Chlorella lewinii SUB3545914 on Glucose as a Carbon Source}

The microalga demonstrated the ability to grow in BG-11 medium supplemented with varying concentrations of glucose under strict heterotrophic condition. Most importantly, under this growth state, the biomass concentrations increased with increase in glucose concentrations. This attribute of heterotrophy is important because of numerous claims that heterotrophic cultures yield more biomasses and lipids in microalgae [9] [11] [12] [13] [14] [15]. Even though this direct relationship exists, increasing the medium glucose will influence the cost of the final product. Liang et al. [31] had previously observed that glucose utilisation by microalgae is dose-dependent, and particularly the microalga Chlorella protothecoides showed that certain concentrations of medium glucose in mixotrophic culture condition may improve growth whereas increased glucose in the medium to up to $10 \%$ became inhibitory to the algal growth.

Although microalgal heterotrophic growth is found to be dependent on glucose concentration [31], the present study showed that the optimum concentration may not be dependent on the stage of growth. This could be attributed to the physiological behavior of the cells and such behavior had previously been reported [17]. The implication of this is that planned or targeted harvesting is necessary to achieve maximal output taking cognizance of the stage of product formation. The maximum biomass density of Chlorella lewinii $\left(3.15 \mathrm{~g} \cdot \mathrm{L}^{-1}\right)$ obtained in the present study was high enough as the condition was not optimized. Future work requiring optimization of the process could yield much higher biomass and is therefore, hereby recommended. Relating this to previous work, 
Liang et al. [31] reported lower biomass yields for a related species of the organism. In a related microalga (Scenedesmus quadricauda), Zhao et al. [32] showed that the level of medium glucose had a significant influence on the growth.

The highest lipid content of Chlorella lewinii was obtained in culture supplemented with the highest medium glucose, presupposing that lipid accumulation is also dependent on the medium glucose dosage. This aspect is very important because for glucose requirement to be high, the cost of production will also be proportionately high. This may have direct effect on the final product and could defeat the aim of lipid production and microalgal biodiesel production feasibility, which is linked to cost. Previous report by Zhao et al. [32] showed that the lipid content of $S$. quadricauda cultured in media containing varying levels of glucose did not follow the same pattern of lipid yields as presented in this study.

\subsection{Heterotrophic Cultivation of Chlorella lewinii SUB3545914 on Glycerol as a Carbon Source}

Chlorella lewinii was also able to grow and accumulate lipids in media containing different concentrations of glycerol. In the present study, the growth of Chlorella lewinii showed a somewhat inverse relationship with the initial medium glycerol concentration. This indicates a probable positive event since large volume would not be needed in order to achieve high biomass. Studies on glycerol utilisation by microalgae for lipid accumulations have been documented [19] [31] [33]. Liang et al. [31] reported that, for Chlorella protothecoides, growth was higher in a medium containing $2 \%$ glycerol which was not supported by the present study. Chen and Walker [19] reported a cell dry weight much higher than those obtained in the present report for a lipid-producing Chlorella protothecoides. A follow-up to this work should include optimization of the growth conditions for maximal results.

The maximum observable lipid accumulated by Chlorella lewinii was at highest medium glycerol concentration, indicating a direct albeit subtle relationship between medium glycerol and lipid content. This observation supports the report of Liang et al. [31] for Chlorella protothecoides. The maximum lipid content of $34 \%$ obtained in glycerol medium is lower than $53 \%$ reported by Chen and Walker [19] for Chlorella protothecoides. The Chlorella strain and the cultivation conditions, including the reactor design and the fluid rheology could account for the different biomass and lipids concentrations obtained by various researchers.

The demonstration that Chlorella lewinii could utilize glycerol for growth and lipid accumulation is important since glycerol is a by-product of biodiesel production. Consequently, the alga could be used to mop up the glycerol generated as waste during biodiesel production, enabling the system to auto-recycle its waste product. The values obtained for maximum biomass and lipid productivities in the present study were higher in glucose medium than in glycerol medium. However, it might be more economical to use crude glycerol from biodiesel plants rather than procure glucose. 
Under heterotrophic cultivation, biomass concentrations were higher for both glucose and glycerol-supplemented media than those obtained in photoautotrophic cultures. This supports the argument that heterotrophic cultures yield more biomass than their autotrophic counterparts [9] [10] [11] [14] [15] [34]. Similarly, lipid accumulation in heterotrophic cultures was significantly higher than the values obtained in photoautotrophic cultures. This also supports dome previous reports [9] [12] [13] [14] [15]. Another major advantage of heterotrophic cultures over the photoautotrophic culture is that it is simpler and cheaper to construct and operate large scale heterotrophic reactors than photobioreactors since light supply and distribution is a big constraint in photobioreactor design and scale up [35].

However, the identification of cheap and easily available carbon sources is a major challenge in making the heterotrophic production of biodiesel oil and other high-volume, low-price products economically viable. To this end, for the use of wastewater that contains significantly high carbon sources that can be utilized by oleaginous microorganisms is a very viable alternative. Although the present study has supported the previous ones that heterotrophic cultures yield more biomass and lipids, yet there is another very significant bottleneck associated with heterotrophic cultivation. Contamination is a big challenge and has to be addressed strictly in any heterotrophic culture design.

Oleic acid (C18:1) obtained as the major fatty acid in the present study is an indicator of the quality of a good biodiesel. Oleic acid [mono-unsaturated fatty acid (MUFA)] along with stearic (Octadecanoic) and linoleic acids are the most common fatty acids associated with biodiesel [36]. Biodiesel production using fungi as feedstock had been demonstrated [37]. However, compared with fungi, lipid productivities by microalgae are much higher. In terms of the biodiesel properties, this study presents no remarkable difference in quality owing to cultivation using glucose or glycerol as the substrate.

\section{Conclusion}

This work has demonstrated, for the first time, that Chlorella lewinii SUB3545914 is capable of growing under heterotrophic cultures using both glucose and glycerol as the carbon sources. The biomass concentrations obtained in heterotrophic cultures with glucose $\left(3.15 \pm 0.13 \mathrm{~g} \cdot \mathrm{L}^{-1}\right)$ and glycerol $\left(2.03 \pm 0.68 \mathrm{~g} \cdot \mathrm{L}^{-1}\right)$ were respectively 5.5 and 2.2 -folds higher than the values obtained in photoautotrophic cultures but the chlorophyll contents of the alga under photoautotrophic culture conditions were 7 times more than the values obtained in heterotrophic cultures. Lipid productivity in heterotrophic culture with glucose was 5.5 times higher than the value obtained in photoautotrophic culture. Consequently, heterotrophic cultivation on glucose was the best culture method for mass cultivation of Chlorella lewini and lipid accumulation.

\section{Conflicts of Interest}

The authors declare no conflicts of interest regarding the publication of this paper. 


\section{References}

[1] Lang, X., Dalai, A.K., Bakhashi, N.N., Reaney, M.J. and Hertz, P.B. (2001) Preparation and Characterization of Bio-Diesels from Various Bio-Oils. Bioresource Technology, 80, 53-62. https://doi.org/10.1016/S0960-8524(01)00051-7

[2] Demirbas, A. (2003) Biodiesel Fuels from Vegetable Oils via Catalytic and Non-Catalytic Supercritical Alcohol Transesterifications and Other Methods: A Survey. Energy Conversion and Management, 44, 2093-2109. https://doi.org/10.1016/S0196-8904(02)00234-0

[3] Chisti, Y. (2007) Biodiesel from Microalgae. Biotechnology Advances, 25, 294-306. https://doi.org/10.1016/j.biotechadv.2007.02.001

[4] Griffiths, J.M. and Harrison, T.L. (2009) Lipid Productivity as a Key Characteristic for Choosing Algal Species for Biodiesel Production. Journal of Applied Phycology, 21, 493-507. https://doi.org/10.1007/s10811-008-9392-7

[5] Schenk, P.M., Thomas-Hall, S.R., Stephens, E., Marx, U.C., Mussgnug, J.H., Posten, C., Kruse, O. and Hankamer, B. (2008) Second Generation Biofuels: High-Efficiency Microalgae for Biodiesel Production. BioEnergy Research, 1, 20-43. https://doi.org/10.1007/s12155-008-9008-8

[6] Hu, Q., Sommerfield, M., Jarvis, E., Ghirardi, M., Posewitz, M., Seibert, M. and Darzins, A. (2008) Microalgal triacylglycerols as Feedstocks for Biofuel Production: Perspectives and Advances. The Plant Journal, 54, 621-639. https://doi.org/10.1111/j.1365-313X.2008.03492.x

[7] Li, X., Hu, H.Y., Gan, K. and Sun, Y.X. (2010) Effects of Different Nitrogen and Phosphorus Concentrations on the Growth, Nutrient Uptake, and Lipid Accumulation of a Freshwater Microalga Scenedesmus sp. Bioresour. Technol., 101, 5494-5500. https://doi.org/10.1016/j.biortech.2010.02.016

[8] Jorquera, O., Kiperstok, A., Sales, E.A., Embirucu, M. and Ghirardi, M.L. (2010) Comparative Energy Life-Cycle Analyses of Microalgal Biomass Production in Open Ponds and Photobioreactors. Bioresource Technology, 101, 1406-1413. https://doi.org/10.1016/j.biortech.2009.09.038

[9] Xu, H., Miao, X.L. and Wu, Q.Y. (2006) High Quality Biodiesel Production from a Microalga Chlorella protothecoides by Heterotrophic Growth in Fermenters. Journal of Biotechnology, 126, 499-507. https://doi.org/10.1016/j.jbiotec.2006.05.002

[10] Cheng, Y., Lu, Y., Gao, C.F. and Wu, Q.Y. (2009) Alga-Based Biodiesel Production and Optimization Using Sugar Cane as the Feedstock. Energy and Fuels, 23, 4166-4173. https://doi.org/10.1021/ef9003818

[11] Azma, M., Mohamed, M.S., Mohamad, R., Rahim, R.A. and Ariff, A.B. (2011) Improvement of Medium Composition for Heterotrophic Cultivation of Green Microalgae, Tetraselmis suecica, Using Response Surface Methodology. Biochemical Engineering Journal, 53, 187-195. https://doi.org/10.1016/j.bej.2010.10.010

[12] Miao, X.L. and Wu, Q. (2006) Biodiesel Production from Heterotrophic Microalgal Oil. Bioresource Technology, 97, 841-846. https://doi.org/10.1016/j.biortech.2005.04.008

[13] Hsieh, C.H. and Wu, W.T. (2009) Cultivation of Microalgae for Oil Production with a Cultivation Strategy of Urea Limitation. Bioresource Technology, 100, 3921-3926. https://doi.org/10.1016/j.biortech.2009.03.019

[14] Ogbonna, J.C. and McHenry, M.P. (2015) Culture Systems Incorporating Heterotrophic Metabolism for Biodiesel Oil Production by Microalgae. In: Moheimani, N.R., McHenry, M.P., Boe, K., et al., Eds., Biomass and Biofuels from Microalgae. 
Advances in Engineering and Biology, Springer International Publishing, Cham, Switzerland, 63-74.

[15] Ogbonna, J.C. and Moheimani, N.R. (2015) Potentials of Exploiting Heterotrophic Metabolism for Biodiesel Oil Production by Microalgae. In: Moheimani, N.R., McHenry, M.P., Boe, K., et al., Eds., Biomass and Biofuels from Microalgae. Advances in Engineering and Biology, Springer International Publishing, Cham, Switzerland, 45-61.

[16] Chiu, S.Y., Kao, C.Y., Chen, C.H., Kuan, T.C., Ong, S.C. and Lin, C.S. (2008) Reduction of $\mathrm{CO}_{2}$ by a High-Density Culture of Chlorella sp. in a Semi-Continuous Photobioreactor. Bioresource Technology, 99, 3389-3396.

https://doi.org/10.1016/j.biortech.2007.08.013

[17] Xiong, W., Li, X., Xiang, J. and Wu, Q. (2008) High-Density Fermentation of Microalga Chlorella protothecoides in Bioreactor for Microbio-Diesel Production. Applied Microbiology and Biotechnology, 78, 29-36.

https://doi.org/10.1007/s00253-007-1285-1

[18] Liu, J., Huang, J., Fan, K.W., Jiang, Y., Zhong, Y., Sun, Z. and Chen, F. (2010) Production Potential of Chlorella zofingienesis as Feedstock for Biodiesel Production.

Bioresource Technology, 101, 8658-8663.

https://doi.org/10.1016/j.biortech.2010.05.082

[19] Chen, Y.H. and Walker, T.H. (2011) Biomass and Lipid Production of Heterotrophic Microalgae Chlorella protothecoides by Using Biodiesel-Derived Crude Glycerol. Biotechnology Letters, 33, 1973-1983. https://doi.org/10.1007/s10529-011-0672-y

[20] Morales-Sánchez, D., Tinoco-Valencia, R., Kyndt, J. and Martinez, A. (2013) Heterotrophic Growth of Neochloris oleoabundans Using Glucose as a Carbon Source. Biotechnology for Biofuels, 6, 100. https://doi.org/10.1186/1754-6834-6-100

[21] Ogbonna, I.O. and Ogbonna, J.C. (2015) Isolation of Microalgae Species from Arid Environments of Northern Nigeria and Evaluation of Their Potentials for Biodiesel Production. African Journal of Biotechnology, 14, 1596-1604. https://doi.org/10.5897/AJB2014.14327

[22] Ogbulie, T.E. and Nwaokorie, F.O. (2016) Molecular Diversity of Microbes with Probable Degradative Genes in Agricultural Soil Contaminated with Bonny Light Crude Oil. Journal of Ecosystem and Ecography, S5, 002.

[23] Liang, Y., Mai, K. and Sun, S. (2005) Differences in Growth, Total Lipid Content and Fatty Acid Composition among 60 Clones of Cylindrotheca fusiformis. Journal of Applied Phycology, 17, 61-65. https://doi.org/10.1007/s10811-005-5525-4

[24] Becker, E.W. (1994) Microalgae: Biotechnology and Microbiology. Cambridge University Press, New York.

[25] Bligh, E.G. and Dyer, W.J. (1959) A Rapid Method of Total Lipid Extraction and Purification. Canadian Journal of Biochemistry and Physiology, 37, 911-917. https://doi.org/10.1139/y59-099

[26] Ogbonna, I.O. and Ogbonna, J.C. (2018) Effects of Carbon Source on Growth Characteristics and Lipid Accumulation by Microalga Dictyosphaerium sp with Potential for Biodiesel Production. Energy and Power Engineering, 10, 29-42. https://doi.org/10.4236/epe.2018.102003

[27] Ogbonna, I.O., Okpozu, O.O., Ikwebe, J. and Ogbonna, J.C. (2018) Utilization of Desmodesmus subspicatus LC172266 for Simultaneous Remediation of Cassava Wastewater and Accumulation of Lipids for Biodiesel Production. Biofuels. https://doi.org/10.1080/17597269.2018.1426164 
[28] Jiménez, R.N., Cerón, G.M.D.C., Sanchez, M.A., Belarbi, H.E.H., García, C.F. and Molina, G.E. (2009) Lipids Accumulation in Chlorella protothecoides through Mixotrophic and Heterotrophic Cultures for Biodiesel Production. New Biotechnology, 25, S266. https://doi.org/10.1016/j.nbt.2009.06.595

[29] Liu, J., Huang, J., Sun, Z.Y., Zhong, Y.J. and Chen, F. (2011) Differential Lipid and Fatty Acid Profiles of Photoautotrophic and Heterotrophic Chlorella zofingiensis. Assessment of Algal Oils for Biodiesel Production. Bioresource Technology, 102, 106-110. https://doi.org/10.1016/j.biortech.2010.06.017

[30] Wu, L.F., Chen, P.C., Huang, A.P. and Lee, C.M. (2012) The Feasibility of Biodiesel Production by Microalgae Using Industrial Wastewater. Bioresource Technology, 113, 14-18. https://doi.org/10.1016/j.biortech.2011.12.128

[31] Liang, Y., Sarkany, N. and Cui, Y. (2009) Biomass and Lipid Productivities of Chlorella vulgaris under Autotrophic, Heterotrophic and Mixotrophic Growth Conditions. Biotechnology Letters, 31, 1043-1049. https://doi.org/10.1007/s10529-009-9975-7

[32] Zhao, G., Yu, J., Jiang, F., Zhang, X. and Tan, T. (2012) The Effect of Different Trophic Modes on Lipid Accumulation of Scenedesmus quadricauda. Bioresource Technology, 114, 466-471. https://doi.org/10.1016/j.biortech.2012.02.129

[33] Pyle, D.J., Garcia, R.A. and Wen, Z.Y. (2008) Producing Docosahexaenoic Acid (DHA) Rich Algae from Biodiesel-Derived Crude Glycerol: Effects of Impurities on DHA Production and Algal Biomass Composition. Journal of Agricultural and Food Chemistry, 56, 3933-3939. https://doi.org/10.1021/jf800602s

[34] Ogbonna, J.C., Tomiyama, S. and Tanaka, H. (1998) Heterotrophic Cultivation of Euglena gracilis $\mathrm{Z}$ for Efficient Production of $\alpha$-Tocopherol. Journal of Applied Phycology, 10, 67-74. https://doi.org/10.1023/A:1008011201437

[35] Ogbonna, J.C., Yada, H. and Tanaka, H. (1995) Light Supply Coefficient-A New Engineering Parameter for Photobioreactor Design. Journal of Fermentation and Bioengineering, 80, 369-376. https://doi.org/10.1016/0922-338X(95)94206-7

[36] Knothe, G. (2008) “Designer" Biodiesel: Optimizing Fatty Ester Composition to Improve Fuel Properties. Energy and Fuels, 22, 1358-1364. https://doi.org/10.1021/ef700639e

[37] Koutb, M. and Morsy, F.M. (2011) A Potent Lipid Producing Isolate of Epicoccum purpurscens AUMC5615 and Its Promising Use for Biodiesel Production. Biomass \& Bioenergy, 35, 3182-3187. https://doi.org/10.1016/j.biombioe.2011.04.050 